\title{
Effect of high pressure high temperature processing on the volatile fraction of differently coloured carrots
}

\author{
Biniam T. Kebede ${ }^{a}$, Tara Grauwet ${ }^{a}$, Stijn Palmers ${ }^{a}$, Liesbeth Vervoort ${ }^{a}$, Reinhold Carle ${ }^{b}$, \\ Marc Hendrickx ${ }^{\mathrm{a}}$, Ann Van Loey ${ }^{\mathrm{a}, *}$ \\ ${ }^{a}$ Laboratory of Food Technology, Leuven Food Science and Nutrition Research Center (LFoRCe), Department of Microbial and Molecular Systems (M²S), \\ KU Leuven, Kasteelpark Arenberg 22 Box 2457, 3001 Heverlee, Belgium \\ ${ }^{\mathrm{b}}$ Institute of Food Science and Biotechnology, Plant Foodstuff Technology, Hohenheim University, Garbenstrasse 25, 70599 Stuttgart, Germany
}

\section{A R T I C L E I N F O}

\section{Article history:}

Received 16 September 2013

Received in revised form 8 December 2013

Accepted 12 December 2013

Available online 21 December 2013

\section{Keywords}

Differently coloured carrot cultivars

Thermal processing

High pressure high temperature processing

Sterilisation

MS-based fingerprinting

Metabolomics

Process-induced chemical reaction

\begin{abstract}
A B S T R A C T
To get deeper insight into the effect of high pressure high temperature (HPHT) processing on the volatile fraction of carrots, differently coloured cultivars exhibiting orange, purple, red and yellow hues were investigated. The impact of HPHT sterilisation was compared with thermal sterilisation based on equivalent microbiological inactivation. The results of this study demonstrated HPHT sterilisation to exert a distinct effect on important chemical reactions in comparison to thermal sterilisation. A comprehensive integration of MS-based metabolomic fingerprinting (HS-SPME-GC-MS) and chemometric tools has been implemented as an untargeted multivariate screening tool to identify differences. In all carrot cultivars, two dominant discriminative quality-related reactions were found: oxidative degradation and the Maillard reaction. Regarding the first reaction, oxidative terpenes, free fatty acids and carotenoids degradation products were detected at higher levels after HPHT sterilisation. Regarding the latter reaction, HPHT sterilisation appeared to suppress the formation of Maillard and Strecker degradation products.
\end{abstract}

(c) 2013 Elsevier Ltd. All rights reserved.

\section{Introduction}

The carrot is a popular vegetable, and its consumption is of high nutritional relevance. Carrot popularity has been attributed to its sweetness and pleasant flavour, satisfying crunch and health benefits. The characteristic aroma and flavour are mainly due to its volatile compounds (Alasalvar, Grigor, Zhang, Quantick, \& Shahidi, 2001) even though other compounds, such as free sugars, non-volatile bitter compounds and free amino acids have also been reported to contribute to the sensory quality. Monoterpenes and sesquiterpenes account for about $98 \%$ of the total volatiles (Kreutzmann, Thybo, Edelenbos, \& Christensen, 2008; Simon, 1982).

Carrots exist in different genotypes, and this genetic variation, cultivation conditions and exposure to ethylene affect the sensorial (e.g., volatiles and polyacetylenes) and nutritional (e.g., carotenoids, vitamins and minerals) attributes (Kramer, Bufler, Nothnagel, Carle, \& Kammerer, 2012a; Kramer et al., 2012b; Leja et al., 2013; Nicolle, Simon, Rock, Amouroux, \& Remesy, 2004; Simon, 1982). Kreutzmann et al. (2008) also underlined the importance of color

\footnotetext{
* Corresponding author. Tel.: +32 163215 72; fax: +32 16321960 .

E-mail addresses: BiniamTamiru.Kebede@biw.kuleuven.be (B.T. Kebede), ann.vanloey@biw.kuleuven.be (A. Van Loe.

URLs: http://www.biw.kuleuven.be/m2s/clmt/lmt/ (B.T. Kebede), http://www. biw.kuleuven.be/lmt/vdt/ (A. Van Loey).
}

genotype on chemical composition, based on their investigation on differently coloured carrot cultivars. In that context, it can be concluded that when investigating the change in carrot quality, for example, as a result of a certain food processing technology, it is important to take into account the variance in the natural chemical composition among the different varieties or in other words to analyse a wide range of varieties to paint a complete picture.

The present study compares the impact of process-induced chemical reactions on carrots processed with high pressure high temperature (HPHT) and conventional thermal sterilisation. HPHT processing is a novel food sterilisation technique. During HPHT processing, there is a fast compression heating and decompression cooling which results in shorter treatment times and consequently a reduced thermal load as compared to conventional thermal sterilisation processes. In that context, one of the unique potentials of HPHT processing could be the possibility to apply the high-temperature short-time principle on solid (conduction-heating) foods (De Heij et al., 2003; Matser, Krebbers, Van den Berg, \& Bartels, 2004; Wilson, Dabrowski, Stringer, Moezelaar, \& Brocklehurst, 2008).

The knowledge about the effect of HPHT processing on food quality and safety related chemical reactions is still limited. Since the aim of this study was to have a better understanding of the beneficial/detrimental effect of HPHT processing on carrots, taking 
into account the possible differences in chemical composition among varieties, cultivars of different colour hues (orange, purple, red and yellow) were chosen. Targeting a fair comparison between the novel and conventional sterilisation, an experimental processing strategy was employed involving the selection of processing conditions in both thermal and HPHT treatments aiming at an equivalent microbial inactivation $\left(F_{0}=5 \mathrm{~min}\right)$ (Brown, 2004).

Due to differing sensitivity of reactions towards pressure and temperature, which are governed by activation volume and activation energy, respectively, the mechanisms and effects of thermal processing at atmospheric pressure might not be extrapolated to processing conditions at higher pressures, and thus, it is possible that HPHT processing could induce different chemical reactions (Oey, Van der Plancken, Van Loey, \& Hendrickx, 2008; Ramirez, Saraiva, Lamela, \& Torres, 2009; Valdez-Fragoso, Mujica-Paz, Welti-Chanes, \& Torres, 2011). In addition, during food processing, chemical reactions such as lipid oxidation, Maillard reaction and carotenoid degradation may interfere. In this context, when following a targeted single/multi-response approach, where only a single reaction product/single reaction pathway is monitored, some important changes may be overlooked. Therefore, in this work, a comprehensive integration of MS-based metabolomic fingerprinting and chemometric tools was used as an untargeted multivariate screening tool (Kebede et al., 2013; Vervoort et al., 2012a, 2013) to identify potential differences between thermal and HPHT sterilised carrot cultivars.

End-products of most of process-induced chemical reactions are often short-chain volatile compounds. For that reason, a headspace-solid phase microextraction-gas chromatography-mass spectrometry (HS-SPME-GC-MS) method was used to analyse the headspace fraction of processed carrots from which characteristic fingerprint chromatograms were obtained and further subjected to multivariate data analysis (MVDA). This fast screening tool might help to identify chemical reactions that are differently affected by HPHT processing and its conventional counterpart and to determine potential markers for this novel food processing technology.

\section{Materials and methods}

\subsection{Sample preparation}

Single batches of freshly harvested carrots of orange (cv. Nerac), purple (cv. Deep purple), red (unknown variety) and yellow (cv. Yellow mellow) were purchased at a local market. The carrots were carefully washed and cut into standardised cylindrical pieces of approximately $1 \mathrm{~cm}$ thickness. The carrots were then put into low density polyethylene bags. To prevent enzymatic reactions during processing, storage and thawing, the packaged carrots were blanched at $95^{\circ} \mathrm{C}$ for $8 \mathrm{~min}$ in a water bath (Haake W15 DC-10, Clausthal-Zellerfeld, Germany). The blanched plastic bags were immediately cooled in ice water for $10 \mathrm{~min}$, frozen in liquid nitrogen and stored in a freezer at $-40{ }^{\circ} \mathrm{C}$. The blanching conditions were validated using a qualitative and quantitative peroxidase test (Adebooye, Vijayalakshmi, \& Singh, 2008; Vervoort et al., 2012b). Prior to processing, the samples were thawed overnight at $4{ }^{\circ} \mathrm{C}$, and a Buchi mixer (B-400, Büchi, Flawil, Switzerland) was used to blend the blanched carrots.

\subsection{Technological processing}

Aiming at objective comparison of technological impacts on the product, the processing conditions in both thermal and HPHT sterilisation were selected targeting an equivalent inactivation of spores of Clostridium botulinum $\left(F_{121.1^{\circ} \mathrm{C}}^{10^{\circ} \mathrm{C}}\left(F_{0}\right)=5 \mathrm{~min}\right)$. A holding temperature $\left(T_{h}\right)$ of $117{ }^{\circ} \mathrm{C}$ was chosen for both processing treatments. Due to the lack of reliable kinetic data as a result of incomplete understanding of the combined effect of pressure and temperature (Van der Plancken et al., 2012), in the present work, the HPHT treatment was considered as pressure assisted thermal treatment; i.e., for calculating the $F_{0}$ value, only the integrated thermal effects derived from the time-temperature profiles were taken into account. Each kind of treatment was repeated 6 times. The profiles of the recorded process for both thermal and HPHT treatment are depicted in Kebede et al. (2013). Due to their inert nature, glass jars and Teflon (polytetrafluoroethylene) sample holders were selected for the thermal and the HPHT processing, respectively.

\subsubsection{Thermal processing}

The thermal treatment was carried out in a static Steriflow pilot retort (Barriquand, Paris, France). The glass jars (100 $\mathrm{ml}$ volume, $95 \mathrm{~mm}$ height and $45 \mathrm{~mm}$ diameter) were filled with $85 \pm 0.5 \mathrm{~g}$ of carrot puree and then closed with metal lids. Next, they were loaded into the retort and sterilised for $80 \mathrm{~min}$. Temperature profiles in the retort and at the coldest point of the product were recorded using type-T thermocouples (Ellab, Hillerød, Denmark).

\subsubsection{High pressure high temperature processing}

The HPHT treatment was carried out in laboratory-scale equipment (custom-made, Resato, The Netherlands), which consisted of six vertically oriented individual vessels (volume $=43 \mathrm{~cm}^{3}$ and diameter $=2 \mathrm{~cm}$ ). The vessels were jacketed with a heating coil connected to a temperature controlling unit. The HPHT equipment allowed computer-controlled pressure build-up to $800 \mathrm{MPa}$, temperature control up to $120^{\circ} \mathrm{C}$ and data logging of both sample pressure and temperature. The pressure medium was $100 \%$ propylene glycol (PG fluid, Resato, The Netherlands). During HPHT treatment, preheating at atmospheric pressure, pressure build-up, holding and cooling steps were established (Grauwet, Van der Plancken, Vervoort, Hendrickx, \& Van Loey, 2010; Grauwet et al., 2012; Kebede et al., 2013; Van der Plancken et al., 2012).

Teflon sample holders (12 mm inner diameter, $85 \mathrm{~mm}$ length, $4 \mathrm{~mm}$ wall thickness; Vink NV Heist-op-den-Berg, Belgium) were filled with carrot puree and closed with a removable cap and vacuum sealed with double plastic bags. The sample holders were preequilibrated at $10{ }^{\circ} \mathrm{C}$ in a cryostat and subsequently loaded into the $\mathrm{HP}$ vessels that were equilibrated at $117^{\circ} \mathrm{C}$. The compression heating cannot raise the temperature of the product from room temperature to the point where inactivation of spores under high pressure is feasible. Therefore, prior to the actual HPHT treatment, the samples were preheated at atmospheric pressure to experimentally determined initial temperature $\left(T_{i}\right) \sim 75{ }^{\circ} \mathrm{C}$. When the desired $T_{i}$ was achieved, pressure in the vessels was increased through indirect compression. During the pressure build-up, two consecutive stages can be identified: (i) instantaneous pressure increase from 0.1 to $150 \mathrm{MPa}$; (ii) further pressure increase until $600 \mathrm{MPa}$ at a rate of $10 \mathrm{MPa} / \mathrm{s}$. After reaching $600 \mathrm{MPa}$ and an equilibration time of $1 \mathrm{~min}$, the individual vessels were isolated. Due to the pressurisation and isolation processes, the temperature inside the product was increased from $T_{i}$ to $117^{\circ} \mathrm{C}$ through compression heating. The product temperature was recorded online and the holding time was adjusted to achieve the targeted $F_{0}$ value of $5 \mathrm{~min}$. On average, the pressure was held for $15 \mathrm{~min}$. At the end of the holding time, the pressure was released from the vessels, which was accompanied with temperature drop inside the product (decompression cooling). 


\subsection{Post-treatment sample handling}

Following treatments, samples were immediately transferred to ice water to stop further reactions. Consequently, treated samples were emptied in a cooling room and transferred to small volume $(10 \mathrm{ml})$ polyethylene terephthalate tubes with a polyethylene cap. Thereafter, the tubes were frozen in liquid nitrogen and stored at $-40{ }^{\circ} \mathrm{C}$ until analysis.

\subsection{HS-SPME-GC-MS analysis}

Samples were thawed overnight in the cooling room $\left(4^{\circ} \mathrm{C}\right)$. Thawed sample $(2.5 \mathrm{~g}$ ) and $2.5 \mathrm{ml}$ saturated $\mathrm{NaCl}$ solution were mixed in a $10-\mathrm{ml}$ amber glass vial $(10 \mathrm{ml}$, VWR International, Radnor, PA, USA). The vials were tightly closed using screw-caps with silicon septum seal (Grace, Columbia, MD), homogenised and transferred to the cooling tray of the autosampler which was maintained at $10{ }^{\circ} \mathrm{C}$. Headspace fingerprinting was conducted on a gas chromatography (GC) system (6890N, Agilent technologies, Diegem, Belgium) coupled to a mass selective detector (MSD) (5973N, Agilent Technologies, Diegem, Belgium) and equipped with a CombiPAL autosampler (CTC analytics, Zwingen, Switzerland). Targeting detection of a wide range of volatiles in a particular food extract, an HS-SPME-GC-MS method of analysis was optimized beforehand. In the selected method, the samples were incubated at $40{ }^{\circ} \mathrm{C}$ for 20 min under agitation at $500 \mathrm{rpm}$. Next, extraction of the volatiles was performed using HS-SPME fiber coated with $30 / 50 \mu \mathrm{m}$ divinylbenzene/carboxen/polydimethylsiloxane (DVB/CAR/PDMS) (StableFlex, Supelco, Bellefonte, PA) at $40^{\circ} \mathrm{C}$ for $10 \mathrm{~min}$. The SPME fiber was inserted into the heated $\left(230^{\circ} \mathrm{C}\right) \mathrm{GC}$ injection port for 2 min to desorb the volatile compounds. Prior to extraction, the fibers were conditioned and regenerated according to the manufacturer's guidelines in the conditioning station of the autosampler. Injection of the samples to the GC column was performed in split (1/5) mode. Chromatographic separation was carried out on an HP-5MS capillary column $(30 \mathrm{~m} \times 0.25 \mathrm{~mm}$ i.d., $0.25 \mu \mathrm{m}$ film thickness, Agilent Technologies, Santa Clara, CA) with helium as carrier gas at a constant flow of $1.5 \mathrm{~mL} / \mathrm{min}$. The GC oven temperature was programmed from a starting temperature of $40^{\circ} \mathrm{C}$, which was retained for $2 \mathrm{~min}$, to $172{ }^{\circ} \mathrm{C}$ at $4{ }^{\circ} \mathrm{C} / \mathrm{min}$, then ramped to $300^{\circ} \mathrm{C}$ at $30^{\circ} \mathrm{C} / \mathrm{min}$ and kept constant at $300{ }^{\circ} \mathrm{C}$ for 2 min before cooling back to $40^{\circ} \mathrm{C}$. The mass spectra were obtained by electron ionisation (EI) mode at $70 \mathrm{eV}$ with a scanning range of $m / z 35-400$ and a scanning speed of 3.8 scans per second. MS ion source and quadrupole temperatures were $230^{\circ} \mathrm{C}$ and $260{ }^{\circ} \mathrm{C}$, respectively.

\subsection{Data pre-processing and multivariate analysis}

As commonly observed in GC-MS analysis, co-eluting compounds were present in the obtained chromatograms. Therefore, all chromatograms were analysed with Automated Mass Spectral Deconvolution and Identification System (AMDIS) (Version 2.66, 2008, National Institute of Standards and Technology, Gaithersburg, MD) to extract "pure" component spectra from complex chromatograms. In addition, AMDIS was used to build a retention index calibration file (for proof of identity along with the mass spectral data). The deconvoluted spectra were then analysed with Mass Profiler Professional (MPP) (Version 12.0, 2012, Agilent Technologies, Diegem, Belgium) for filtering and peak alignment. MPP yielded a spreadsheet containing peak areas, which was used as an input for the statistics. The multivariate data were analyzed with multivariate data analysis (MVDA) which was carried out in Solo (Version 6.5, 2011; Eigenvector Research, Wenatchee, WA). As a pre-processing step, all data were mean-centered, and the variables were weighed by their standard deviation to give them equal variance. To compare the treatment impact, a regressionbased supervised classification technique, namely partial least squares discriminant analysis (PLS-DA) was implemented. For PLS-DA, the volatile compounds were considered as $X$-variables. To investigate the effect of conventional thermal and HPHT sterilisation on differently coloured carrots (Section 3.1), the three classes, blanched (reference), thermal and HPHT processing, were considered as categorical $Y$-variables and to study the effect of differently coloured carrot cultivars after processing (Section 3.2), the four classes, orange, purple, red and yellow carrot cultivars were considered as categorical $Y$-variables. For determining the complexity of the model, the lowest number of latent variables (LVs) resulting in a class separation were used. In PLS-DA, to investigate impact differences among the classes, bi-plots were plotted. To select discriminant volatile compounds, variable identification (VID) coefficients were calculated (Kebede et al., 2013; Vervoort et al., 2012a, 2013). These values correspond to the correlation coefficient between each original $X$-variable and predicted $Y$-variable (s). Variables with an absolute VID value higher than 0.800 were considered to be important. These discriminant volatiles were plotted individually as a function of processing (see Section 3.1) and as a function of carrot cultivar (see Section 3.2). In these plots, the mean areas and the standard errors calculated from the six replicates were depicted. All plots were made using OriginPro 8 (Origin Lab Corporation, Northampton, MA). Duncan's multiple comparison test was used to test for significant differences between the mean peak areas $(p<0.05)$ of the discriminant volatiles. Identification of these compounds was performed by comparing the deconvoluted mass spectrum with the reference mass spectra from both NIST spectral library (NIST08, version 2.0, National Institute of Standards and Technology, Gaithersburg, MD) and Wiley registry of mass spectral data (Wiley 2010, version 9, Hoboken, New York, NY). A threshold match of $90 \%$ was implemented and for confirmation further visual inspection of the spectral matching was conducted. Those compounds with threshold match of below $90 \%$ were put as unidentified. Out of the identified volatiles, to put focus on the most discriminative ones, those with a total peak area difference of $\geqslant 90 \%$, compared to at least in one of the other classes, are listed in italics. In addition, compounds detected only in one class, which can be potential markers, are in bold italics.

\section{Results and discussion}

In this work, the impact on process-induced chemical reactions was compared in differently coloured carrots sterilised by thermal and HPHT processing. For both treatments, the processing conditions were selected targeting at an equivalent microbial inactivation $\left(F_{0}=5 \mathrm{~min}\right)$. Designing a processing from an equivalent point of view guarantees unbiased comparison between different processing technologies. In addition, this approach allowed insight into the integrated effect of all processing variables. However, since the effect of a specific processing variable is not investigated as a function of time with the present experimental set-up, it is not straightforward to attribute process-induced changes to one of the process variables in particular. In this context, this experimental processing approach, combined with MS-based metabolomic fingerprinting (HS-SPME-GC-MS), was investigated in this work as a fast screening method for food quality changes and differences.

The HS-SPME-GC-MS procedure gave chromatograms with high numbers of volatile compounds. Representative examples of GC-MS total ion chromatograms of the blanched orange, purple, red and yellow carrot cultivars are presented in Fig. 1. From these chromatograms, it was clear that red carrot has clearly higher abundance peaks, most of them identified as terpenes. This is in agreement with the literature; red carrot is reported to contain a 

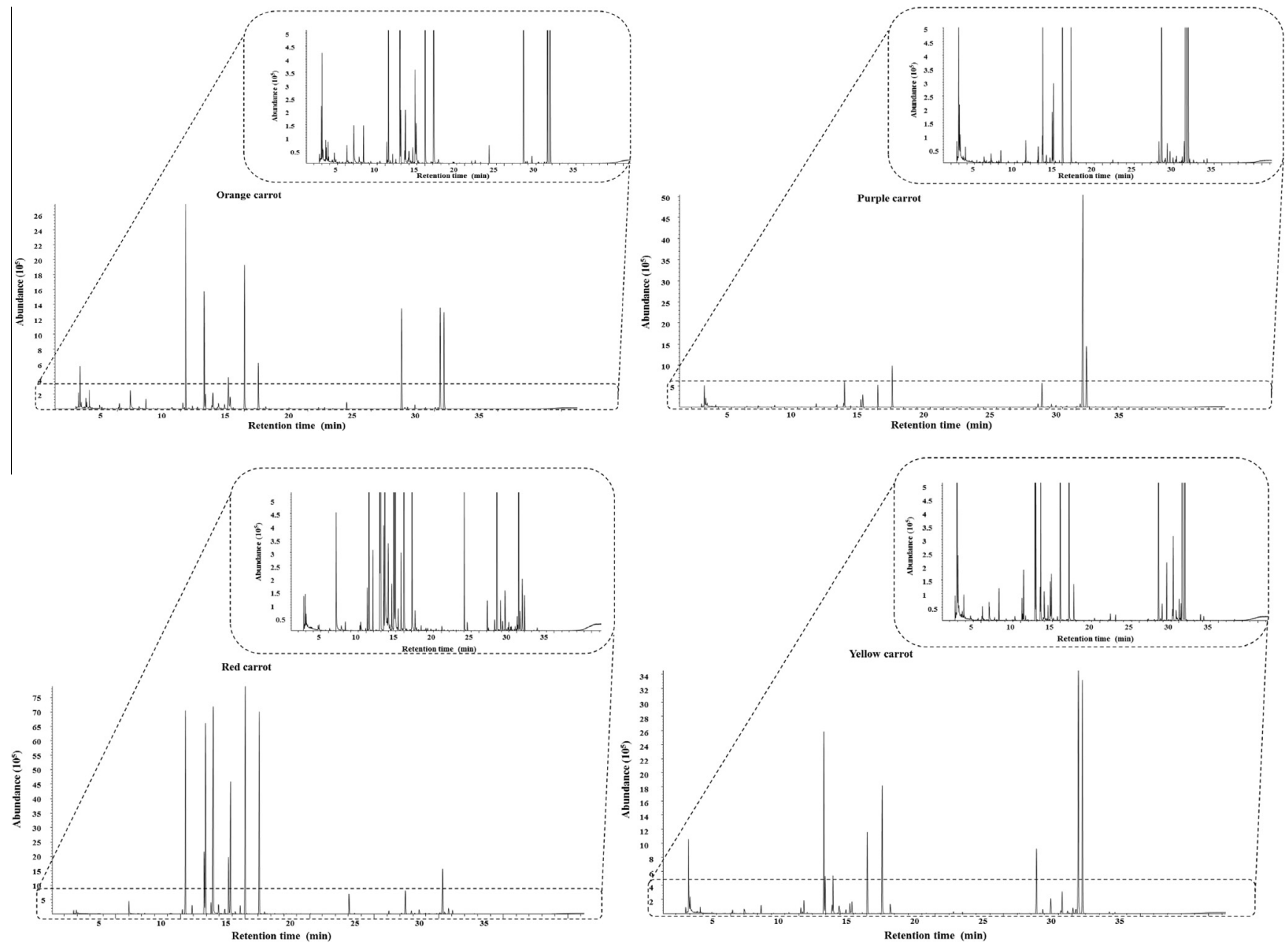

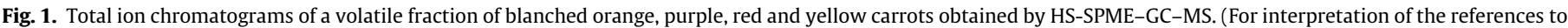
colour in this figure legend, the reader is referred to the web version of this article.)

higher amount of terpenes (Kreutzmann et al., 2008). In addition, yellow and orange carrots seemed to have comparable chromatograms, whereas the chromatogram of purple carrot had the lowest number of volatile compounds detected.

The GC-MS data were investigated at two levels using MVDA Firstly, the effect of conventional thermal and HPHT sterilisation on differently coloured carrots was investigated (Section 3.1). For this purpose, the comparison was initiated per carrot cultivar (Section 3.1.1). Next, to identify process-induced chemical changes that show a comparable trend over all carrot varieties, the comparison was performed without considering the information on carrot colour cultivars (Section 3.1.2). Secondly, to investigate differences which might be caused by the different chemical composition between the carrot varieties, the effect of differently coloured carrot cultivar after each processing was studied (Section 3.2).

\subsection{Effect of conventional thermal and HPHT sterilisation on differently coloured carrots}

\subsubsection{Comparison per carrot colour cultivar}

The obtained chromatograms were analysed with a sequence of data pre-processing techniques, i.e. AMDIS and MPP, (Section 2.5). The data set obtained from MPP was used for MVDA, where partial least squares discriminant analysis (PLS-DA) was applied per carrot cultivar. Since adding an additional latent variable (LV) did not improve the performance of the model, two LVs were selected as optimal. Fig. 2A shows a bi-plot using LV1 and LV2 for orange, purple, red and yellow carrots. A bi-plot is a tool to graphically observe groupings and/or separations between differently processed carrot classes and also to obtain information about volatiles that are highly affected by a certain processing technique. For instance, classes that are close to each other on the bi-plots are considered similar and classes that are far away from each other are considered different. In that context, for all carrot cultivars, there is a separation between the three classes representing blanched, thermal and HPHT processed carrots, showing the different effect of the applied processing technology on the analysed volatile fractions. In that context, $98 \%, 84 \%, 96 \%$ and $93 \%$ of the variance between classes is explained with the two LVs in orange, purple, red and yellow cultivars, respectively. From Fig. 2A, the separation among the three classes of purple carrot is less clear compared to the other cultivars, which is also evident by the lower $Y$-variance explained with the two LVs. Some HPHT-treated purple carrots are spread in the direction of blanched carrots, indicating a possible similarity of their volatile fractions.

On the bi-plots, inner and outer ellipses describe a correlation coefficient of $70 \%$ and $100 \%$, respectively. If volatiles are projected far away from the centre of the coordinate, beyond the inner ellipse, more than $70 \%$ of their variability is explained with two LVs. In other words, the importance of individual volatiles for the discrimination of differently processed carrots maximizes as a function of their distance from the centre of the coordinate. For example, if a volatile compound is detected with a higher amount in HPHT sterilised carrots compared to thermal sterilised carrots, 


\section{A: per carrot cultivar}
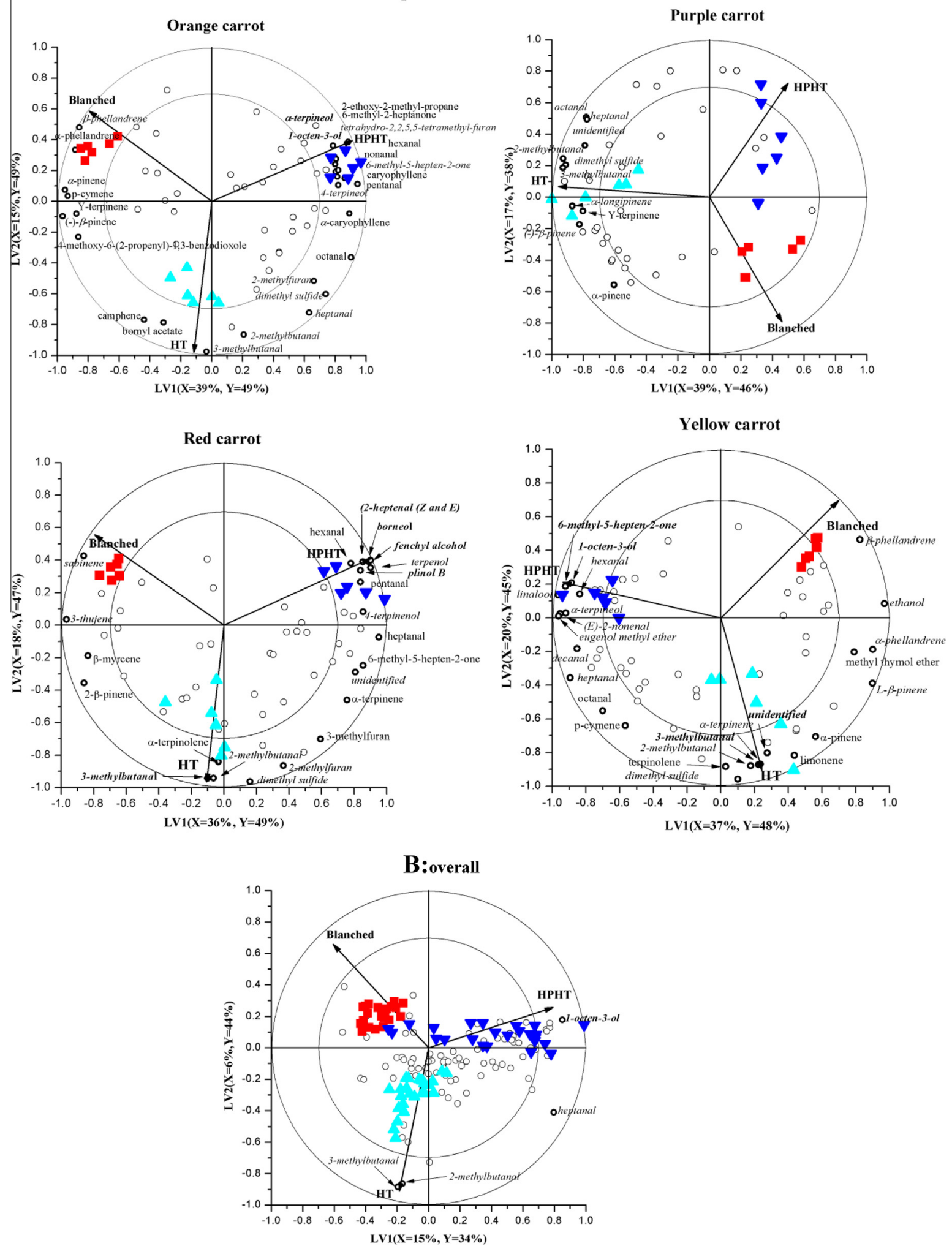

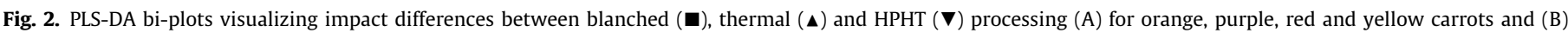

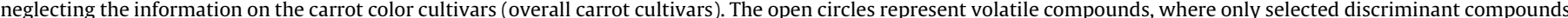

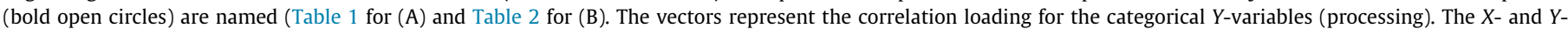

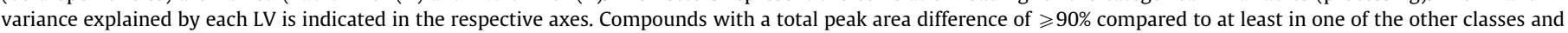

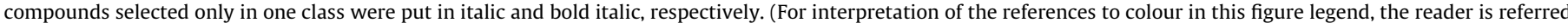
to the web version of this article.)

this compound should be located close to class of HPHT sterilised carrots, whereas if it is less abundant, it should be projected to the opposite side of the HPHT class. On the bi-plots, there are vectors pointing towards each class, representing the correlation 
Table 1

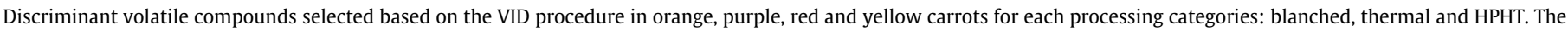

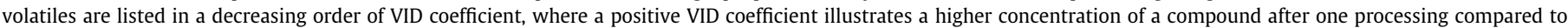

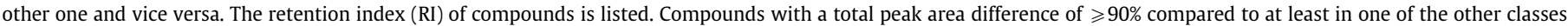
and compounds selected only in one class were put in italic and bold italic, respectively.

\begin{tabular}{|c|c|c|c|c|c|c|c|c|c|}
\hline & \multicolumn{3}{|c|}{ Blanched } & \multicolumn{3}{|c|}{ Thermal processing } & \multicolumn{3}{|c|}{ HPHT processing } \\
\hline & VID & Identity & RI & VID & Identity & RI & VID & Identity & RI \\
\hline \multirow{18}{*}{ Orange carrot } & -0.973 & Octanal & 1003 & & & & -0.957 & $(-)$ - $\beta$-Pinene & 975 \\
\hline & -0.923 & Dimethyl sulfide & 705 & & & & -0.899 & $\alpha$-Pinene & 932 \\
\hline & -0.875 & Heptanal & 902 & & & & -0.894 & 4-Methoxy-6-(2-propenyl)-1,3-benzodioxole & 1550 \\
\hline & -0.844 & $\alpha$-Caryophyllene & 1470 & & & & -0.893 & p-Cymene & 1025 \\
\hline & -0.817 & 2-Methylfuran & 721 & & & & -0.867 & $\gamma$-Terpinene & 1060 \\
\hline & -0.812 & Pentanal & 750 & & & & & & \\
\hline & 0.837 & $(-)$ - $\beta$-Pinene & 975 & 0.811 & 2-Methylbutanal & 736 & 0.820 & 4-Terpineol & 1179 \\
\hline & 0.862 & p-Cymene & 1025 & 0.830 & Bornyl acetate & 1290 & 0.828 & Nonanal & 1106 \\
\hline & 0.895 & $\alpha$-Pinene & 932 & 0.836 & Camphene & 947 & 0.828 & Caryophyllene & 1428 \\
\hline & 0.943 & $\alpha$-Phellandrene & 926 & 0.966 & 3-Methylbutanal & 733 & 0.835 & Tetrahydro-2,2,5,5-tetramethyl-furan & 786 \\
\hline & 0.980 & $\beta$-Phellandrene & 973 & & & & 0.842 & $\alpha$-Caryophyllene & 1470 \\
\hline & & & & & & & 0.843 & 2-Ethoxy-2-methyl-propane & 723 \\
\hline & & & & & & & 0.844 & Hexanal & 812 \\
\hline & & & & & & & 0.850 & 6-Methyl-2-heptanone & 930 \\
\hline & & & & & & & 0.854 & 1-Octen-3-ol & 980 \\
\hline & & & & & & & 0.872 & 6-Methyl-5-hepten-2-one & 987 \\
\hline & & & & & & & 0.942 & Pentanal & 750 \\
\hline & & & & & & & 0.954 & $\alpha$-Terpineol & 1192 \\
\hline \multirow[t]{12}{*}{ Purple carrot } & -0.939 & Octanal & 1003 & & & & -0.899 & $\alpha$-Pinene & 932 \\
\hline & -0.930 & Heptanal & 902 & & & & & & \\
\hline & -0.817 & 2-Methylbutanal & 736 & & & & & & \\
\hline & & & & 0.816 & Heptanal & 902 & & & \\
\hline & & & & 0.825 & Octanal & 1003 & & & \\
\hline & & & & 0.827 & $\alpha$-Longipinene & 1543 & & & \\
\hline & & & & 0.832 & Unidentified & 1589 & & & \\
\hline & & & & 0.834 & $\gamma$-Terpinene & 1060 & & & \\
\hline & & & & 0.843 & (-)- $\beta$-Pinene & 975 & & & \\
\hline & & & & 0.922 & Dimethyl sulfide & 705 & & & \\
\hline & & & & 0.950 & 3-Methylbutanal & 733 & & & \\
\hline & & & & 0.950 & 2-Methylbutanal & 736 & & & \\
\hline \multirow[t]{14}{*}{ Red carrot } & -0.886 & Heptanal & 902 & & & & -0.927 & 2 - $\beta$-Pinene & 975 \\
\hline & -0.883 & $\alpha$-Terpinene & 1016 & & & & -0.910 & 3-Thujene & 926 \\
\hline & -0.876 & 6-Methyl-5-hepten-2-one & 987 & & & & -0.853 & $\beta$-Myrcene & 991 \\
\hline & -0.852 & Unidentified & 1223 & & & & & & \\
\hline & -0.842 & 3-Methylfuran & 721 & & & & & & \\
\hline & 0.889 & 3-Thujene & 926 & 0.798 & 2-Methylfuran & 718 & 0.840 & 4-Terpinenol & 1178 \\
\hline & 0.970 & Sabinene & 971 & 0.837 & $\alpha$-Terpinolene & 1090 & 0.860 & Hexanal & 812 \\
\hline & & & & 0.928 & Dimethyl sulfide & 705 & 0.880 & Pentanal & 750 \\
\hline & & & & 0.940 & 2-Methylbutanal & 736 & 0.884 & Heptanal & 902 \\
\hline & & & & 0.947 & 3-Methylbutanal & 733 & 0.902 & Plinol B & 1149 \\
\hline & & & & & & & 0.932 & 2-Heptenal ( $Z$ and $E$ ) & 956 \\
\hline & & & & & & & 0.966 & $\alpha$-Terpineol & 1191 \\
\hline & & & & & & & 0.967 & Borneol & 1167 \\
\hline & & & & & & & 0.981 & Fenchyl alcohol & 1115 \\
\hline \multirow[t]{13}{*}{ Yellow carrot } & -0.930 & Heptanal & 902 & & & & -0.950 & L- $\beta$-pinene & 975 \\
\hline & -0.891 & Octanal & 1003 & & & & -0.942 & Ethanol & 699 \\
\hline & -0.837 & p-Cymene & 1025 & & & & -0.919 & $\alpha$-Phellandrene & 926 \\
\hline & & & & & & & -0.812 & Methyl thymol ether & 1237 \\
\hline & 0.828 & Ethanol & 699 & 0.841 & Terpinolene & 1090 & 0.811 & Decanal & 1206 \\
\hline & 0.938 & $\beta$-Phellandrene & 973 & 0.847 & Unidentified & 1123 & 0.823 & Heptanal & 902 \\
\hline & & & & 0.854 & $\alpha$-Pinene & 932 & 0.849 & Hexanal & 812 \\
\hline & & & & 0.887 & 2-Methylbutanal & 736 & 0.908 & 1-Octen-3-ol & 979 \\
\hline & & & & 0.895 & 3-Methylbutanal & 733 & 0.912 & $\alpha$-Terpineol & 1192 \\
\hline & & & & 0.896 & $\alpha$-Terpinene & 1016 & 0.940 & 6-Methyl-5-hepten-2-one & 987 \\
\hline & & & & 0.916 & Limonene & 1029 & 0.944 & (E)-2-nonenal & 1162 \\
\hline & & & & 0.936 & Dimethyl sulfide & 705 & 0.951 & Eugenol methyl ether & 1406 \\
\hline & & & & & & & 0.974 & Linalool & 1102 \\
\hline
\end{tabular}

loading for the categorical $Y$-variables (classes). The length and the position of the vectors is a good indication about the performance of the model; i.e., the longer the vectors and the more they are projected towards their respective class shows that indeed proper number of LVs are selected for the PLS-DA model. In that way, biplots provide relevant graphical information about volatiles that relate to a specific processing technology. However using bi-plot, it is not straightforward to rank volatiles based on their concentration after one processing technique compared to another one. For that reason, VID coefficients were calculated (Section 2.5). Per class, each volatile was assigned with a value between -1 and +1 , where a positive VID coefficient represents a higher concentration in that 
class compared to the other class and vice versa. Since the objective was to determine compounds highly formed in a clearly different concentration due to one process compared to the other, only those with absolute value higher than 0.800 (discriminant volatiles) were selected and identified (Table 1; Fig. 2A (bold open circles)). In orange, purple, red and yellow carrots, 27, 10, 22 and 24 discriminant volatile compounds were chosen, respectively. Those compounds with threshold match of below $90 \%$, during the identification process, were listed as unidentified.

In addition to fingerprinting the volatile fraction and identifying discriminative volatiles, the challenge was to investigate possible reaction pathways responsible for the formation of these compounds. For this purpose, it was tried to interpret the identity of selected discriminant volatiles and to link them with possible reaction pathways based on previous findings.

Discriminative volatile compounds that are selected in all carrot cultivars can be categorised under terpene, aldehyde, alcohol, phenylpropanoid, furanic and sulfur-containing chemical classes. In carrot, the formation of these volatiles can be linked to chemical reactions such as terpene degradation, unsaturated fatty acid oxidation, oxidative carotenoid degradation, Maillard, Strecker degradation and degradation of sulfur-containing amino acids.

Terpenes are secondary metabolites synthesised from isoprene units (5 carbon basic building blocks) (Can Baser \& Demirci, 2007). Plants use two biosynthetic pathways leading to the central intermediates for all isoprenoids: the mevalonate pathway within the cytosol and the mevalonate-independent methylerythritol phosphate pathway that operates within plastids. The latter pathway is responsible for the synthesis of monoterpenoids, diterpenoids and tetraterpenoids, whereas sesquiterpenoids and triterpenoids are largely synthesised by the cytosolic mevalonate pathway (Hampel, Mosandl, \& Wust, 2005; Jones, 2008). As discussed earlier, terpenoids produce a wide range of flavours and aromas contributing to the sensory appearance of carrot. For example, monoterpenoids such as (+)-sabinene, $\beta$-myrcene, $p$-cymene, $(+)$ - and $(-)$ - $\alpha$-pinene, $(+)$ - and $(-)$ - $\beta$-pinene and $(-)-\alpha$-phellandrene were shown to be responsible for the 'green', 'pine' and 'terpene-like' aroma, while sesquiterpenoids such as $\beta$ caryophyllene and $\alpha$-humulene were reported to produce 'spicy' and 'woody' notes in carrots (Jones, 2008; Kjeldsen, Christensen, \& Edelenbos, 2003). In the present work, most of these volatiles were detected as discriminant compounds. In all carrot cultivars, thermal and HPHT sterilisation lowered the levels of the majority of terpenes. Nevertheless, the lowest terpene concentrations were detected in HPHT-treated carrots. In addition, higher amounts of monoterpene alcohols (e.g., 4-terpineol and $\alpha$-terpineol) were detected after HPHT sterilisation. Formation of terpene alcohols is linked to oxidative processes, in which the tetra-substituted terpenes double bond is attacked (Jones, 2008; Kjeldsen et al., 2003). It can be hypothesised that high pressure is enhancing oxidative conversion of some terpenes to terpene alcohols, resulting in clearly lower terpene concentrations. These results are in agreement with the observation by Vervoort et al. (2013) who also reported an increased concentration of terpene alcohols ( $\alpha$-terpineol) in orange carrots after HPHT processing in comparison to an equivalent thermal processing.

In general, the reduction in genuine terpenes might magnify the desired sweet carrot flavour through reducing the harsh or burning-like flavour, which is mostly associated with elevated terpene concentration (Howard et al., 1995). Nevertheless, in case of their excessive reduction, the characteristic carrot aroma may be significantly affected. Therefore, there is a need for studies investigating the effect of HPHT processing on carrot flavour.

Fatty acids are precursors of a large number of volatile compounds of which many are important character-impact aroma compounds responsible for the fresh, green and fruity notes.
Degradation of fatty acids occurs mainly through the following reaction pathways: (i) enzyme-catalysed, e.g., $\alpha$ - and $\beta$-oxidation and oxidation via lipoxygenase; (ii) non-enzymatic oxidations, e.g., autoxidation and thermally induced oxidation (Christensen, Edelenbos, \& Kreutzmann, 2007; Reineccius, 2006). The action of different enzymes (e.g., $\alpha$-dioxygenase, acyl CoA hydrolase, lipoxygenase, hydroperoxide lyase) is crucial in the mechanism of the enzyme-catalysed reaction pathways. In the present work, since the carrots were blanched prior to sterilisation, these enzyme-related pathways were not expected to play a major role in the formation of fatty acid degradation volatiles. Nevertheless, it should be noted that the first stage of enzyme-catalysed reactions may already be initiated when cutting the carrots prior to blanching. Autoxidation is a free radical chain process. Factors like temperature, metal ions and light initiate the first stage of the reaction resulting in free radical formation. Once the free radicals are formed, they react in autocatalytic mode to generate a series of intermediate and final reaction products (Christensen et al., 2007). Finally, unsaturated fatty acids also seem to undergo oxidative breakdown during high temperature processing. The mechanism of thermally induced oxidation of unsaturated fatty acids is not fully understood, but possibly involves a series of steps such as hydrogen radical abstraction from the fatty acid backbone, formation of peroxide radical which will further transform into hydroperoxide and finally decomposition to form volatiles (Reineccius, 2006). Furthermore, the reaction might involve decomposition of already formed hydroperoxides and oxidation of volatile compounds from other (non-)enzymatic oxidation pathways (Christensen et al., 2007). Since high temperatures make more sites available on the fatty acid for oxidation, unique volatile compounds are formed at higher temperature compared to at room temperature (Reineccius, 2006). Numerous acids, alcohols, aldehydes, hydrocarbons, ketones, lactones and esters are some of the products of thermally-induced oxidation. In this work, in comparison to blanched carrots, both thermal and HPHT sterilisation increased the concentration of aliphatic aldehydes, alcohols and hydrocarbons in all carrot cultivars. However, formation of such volatiles was more pronounced by HPHT sterilisation compared to thermal sterilisation. A comparable research result was also observed in our previous study (Kebede et al., 2013).

Phenylpropanoids are a diverse class of organic compounds that are synthesised from the amino acid phenylalanine. In this work, these polyphenols (e.g. myristicin in orange carrot and methyl thymol ether in yellow carrot) were detected at comparable levels in blanched and thermally sterilised carrots. However, their concentration was significantly lower after HPHT processing. In yellow carrot, a higher amount of eugenol methyl ether was detected following HPHT processing, and thus it can be hypothesised that HPHT sterilisation may enhance the conversion of methyl thymol ether to eugenol methyl ether.

Carotenoids are yellow, orange and red tetra-terpene pigments responsible for the natural colour of carrots. Different mechanisms are involved in the degradation of these unsaturated and labile structures, e.g. isomerisation, oxidation and thermal degradation, which will result in cleavage of several bonds located at the central region of the molecule to yield (non-)volatile compounds (Crouzet, 2000). However, studies devoted to the identification of volatile compounds generated through such reactions are scarce. The results of the present work demonstrated that known carotenoid degradation-related compounds (e.g. 6-methyl-5-hepten-2-one) (Crouzet, 2000; Kanasawud \& Crouzet, 1990; Kjeldsen et al., 2003) were apparently formed as a result of both conventional and HPHT sterilisations. Nevertheless, these volatiles were detected at higher concentrations after HPHT sterilisation.

Remarkably, the above mentioned important degradation reactions (i.e. terpenes, free fatty acids, phenylpropanoids and carote- 
noids) have one reaction pathway in common, namely oxidation. The present work demonstrated that these oxidative reactions are favoured by high pressure. This is in agreement with previously reported findings, where oxidative chemical reactions were proven to be enhanced by increased pressure (Kebede et al., 2013; Oey et al., 2008; Van der Plancken et al., 2012; Verbeyst, Bogaerts, VanderPlancken, Hendrickx, \& VanLoey, 2012). In our opinion, the fact that HPHT processing, compared to an equivalent conventional thermal processing, is enhancing formation of oxidationrelated reaction products requires further kinetic studies to increase insight into the way processing variables are controlling this network of quality-related reactions. In addition, the observed modification of the volatile fraction of carrots, due to these reactions, should also be investigated from a sensorial point of view.

In addition to oxidation, the Maillard reaction also seems to be differently affected by the conventional and HPHT sterilisation techniques. The Maillard reaction is a non-enzymatic reaction between reducing sugars and compounds with amino group such as free amino acids or proteins, occurring during high temperature processing and storage of foods (Jaeger, Janositz, \& Knorr, 2010; Kerler, Winkel, Davidek, \& Blank, 2010; Mottram, 2007). Various aroma volatiles such as aldehydes, furfurals, furanic compounds, pyrroles, sulfur-containing compounds and other carbonyls can be mentioned in this context (Kerler et al., 2010; Mottram, 2007; Reineccius, 2006). In the present work, both conventional and HPHT sterilisation increased the concentration of furanic compounds (e.g. 2-methylfuran in orange carrot and 2-methylfuran and 3-methylfuran in red carrot) from undetectable levels in blanched carrots, to a higher level. These compounds were detected with a significantly higher amount in thermally heated samples. Some other studies linked the formation of such furanic volatiles to other reaction pathways (besides Maillard reaction), such as unsaturated fatty acid degradation (Mark, Pollien, Lindinger, Blank, \& Mark, 2006) and carotenoids (Owczarek-Fendor et al., 2011) and/or recombination of fragments obtained from various precursors, such as sugars, amino acids and ascorbic acids (Limacher, Kerler, Conde-Petit, \& Blank, 2007).

The Strecker degradation of amino acids is another important step of the Maillard reaction. The reaction involves oxidative deamination and decarboxylation of $\alpha$-amino acids (e.g. alanine, valine, isoleucine and leucine) in the presence of $\alpha$-dicarbonyl compounds which are formed during Maillard reaction (Cremer \& Eichner, 2000a; Kerler et al., 2010). This reaction yields a so-called Strecker aldehyde, containing one carbon atom less than the original acid. In this work, in all four carrot cultivars, the concentration of Strecker aldehydes (e.g. 2-methylbutanal and 3-methylbutanal) was increased after thermal sterilisation compared to equivalent HPHT sterilisation. In agreement with previous findings (Cremer \& Eichner, 2000b; Duan \& Barringer, 2012), the higher the thermal load of conventional thermal sterilisation, the more low odor threshold volatiles that are formed.

In conclusion, the results of the present study demonstrate the potential of HPHT processing to reduce the formation of Maillard and Strecker degradation products. Even though data concerning the effect of HPHT on overall Maillard reaction are still limited, the observation of the present work is consistent with the findings of the few available reports (De Vleeschouwer, Van der Plancken, Van Loey, \& Hendrickx, 2010; Hill, Isaacs, Ledward, \& Ames, 1999; Kebede et al., 2013; Vervoort et al., 2013).

Sulfur-containing amino acids are other important flavour precursors, requiring a secondary transformation upon cell disruption to release the volatiles. In carrots, this transformation has been reported to be accelerated during thermal processing, e.g. through the decomposition of S-methylmethionine to form compounds responsible for a typical canned flavour (Araya et al., 2009; Heatherb, Wrolstad, \& Libbey, 1971). In line with the above discussion, in the present work, in all carrot cultivars, sulfur-containing compounds (e.g. dimethyl sulfide) were preferentially formed after thermal sterilisation. A comparable observation was also previously reported in other studies (Kebede et al., 2013; Vervoort et al., 2013).

Besides the above discussed general trends, some exceptions on process-induced reactions were also observed among the differently coloured carrots. For instance, in purple carrot, aliphatic aldehydes (octanal and heptanal) were detected at higher levels in thermal sterilised samples compared to HPHT sterilised ones. These findings are in contrast to the literature, where formation of these flavour compounds is linked to unsaturated fatty acids degradation, which has been reported to be accelerated under increased pressure (Kebede et al., 2013; Oey et al., 2008; Van der Plancken et al., 2012; Verbeyst et al., 2012). In orange carrot, tetrahydro-2,2,5,5-tetramethylfuran, was detected at significantly higher amounts following HPHT treatment compared to conventional sterilisation. The formation of this compound can be linked to the Maillard reaction and/or carotenoid degradation reaction. Even though both sterilisation technologies reduced the majority of them, some terpenes (e.g. $\gamma$-terpinene, $\alpha$-terpinolene and terpinolene in purple, red and yellow carrots, respectively) were detected at higher levels after conventional sterilisation than after HPHT processing. Terpinolene has been associated with cooked carrot flavour and cooked aftertaste (Howard et al., 1995) and the increased thermal load during thermal sterilisation possibly enhanced their formation.

Compounds that were solely detected in one of the different sterilisation processes invite particular interest as they may be excellent markers for their respective processing technology. In orange carrot, 1 -octen-3-ol and $\alpha$-terpineol were exclusively detected after HPHT treatment. In red carrot, 2-heptenal ( $Z$ and $E$ ), borneol, pinol B and fenchyl alcohol were only detected following HPHT processing, whereas 3-methylbutanal seems to be an indicator of conventional thermal processing. In yellow carrot, 6-methyl5-hepten-2-one and 1-octen-3-ol were detected after HPHT treatment, while 3-methylbutanal was typical of thermal sterilisation. Nevertheless, there is a need to increase insight on the effect of the respective processing parameters on the formation of these volatiles.

\subsubsection{Comparison without considering the information on carrot colour cultivars}

When the process impact was compared per carrot cultivar (Section 3.1.1), some general trends regarding process-induced chemical reactions (e.g., oxidation and Maillard) were observed. It was considered if these trends were consistent when the information on the carrot colour was not considered for the PLS-DA model. Consequently, as a second level of comparative study, we tried to identify important chemical reactions that discriminate the impact of HPHT and thermal sterilisation overall. Therefore, a PLS-DA model was constructed using three latent variables (LVs). The three LVs explained $81 \%$ of the $Y$-variance. A bi-plot (Fig. 2B), with the first two LVs, shows a fair separation between the classes of thermal and HPHT sterilised carrots. However, some HPHT sterilised carrots were situated close to blanched carrots. As previously discussed in Section 3.1.1, these are HPHT sterilised purple carrots showing similarity with the volatile fraction of their blanched counterparts.

As discussed in Section 3.1.1, to rank volatiles based on their concentration in one class compared to the other, VID coefficients were calculated. In that context, the selected discriminative volatile compounds (Table 2; Fig. 2B (open bold circles)) were: heptanal (aliphatic aldehyde), 1-octen-3-ol (alcohol) and 2-methylbutanal and 3-methylbutanal (Strecker aldehydes). 
Table 2

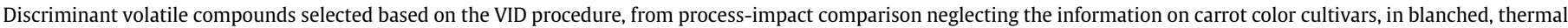

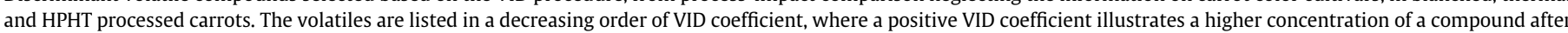

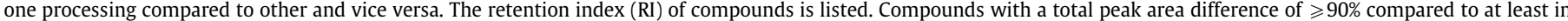
one of the other classes and compounds selected only in one class were put in italic and bold italic, respectively.

\begin{tabular}{|c|c|c|c|c|c|c|c|c|}
\hline \multicolumn{3}{|c|}{ Blanched } & \multicolumn{3}{|c|}{ Thermal processing } & \multicolumn{3}{|c|}{ HPHT processing } \\
\hline VID & Identity & RI & VID & Identity & RI & VID & Identity & RI \\
\hline \multirow[t]{3}{*}{-0.890} & Heptanal & 902 & & & & & & \\
\hline & & & 0.800 & 2-Methylbutanal & 736 & 0.869 & 1-Octen-3-ol & 979 \\
\hline & & & 0.829 & 3-Methylbutanal & 733 & & & \\
\hline
\end{tabular}

Free fatty acids degradation products, heptanal and 1-octen-3ol, were detected at higher concentrations in sterilised variants compared to blanched ones. Among differently sterilised carrots, their concentration was significantly higher in the HPHT-treated samples. Special interest was given to the oxidative linoleic break- down product, 1-octen-3-ol, since it was detected only after HPHT sterilisation, which could make it an interesting marker for HPHT processing technology (in bold italics in Fig. 2B and Table 2).

The concentration of the two Strecker aldehydes was below the detection limits in blanched carrots. Among the sterilised classes,

\section{Blanched/Reference}

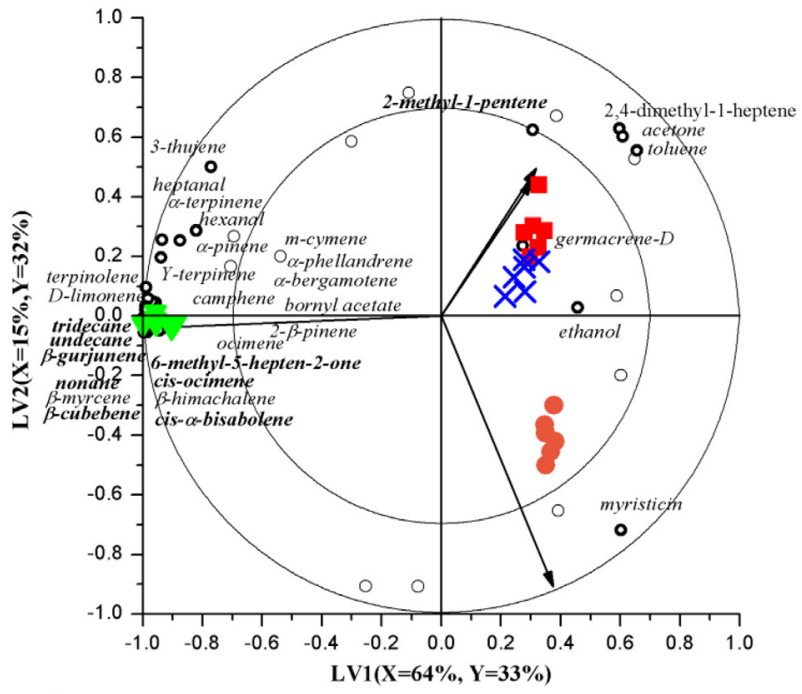

Thermal

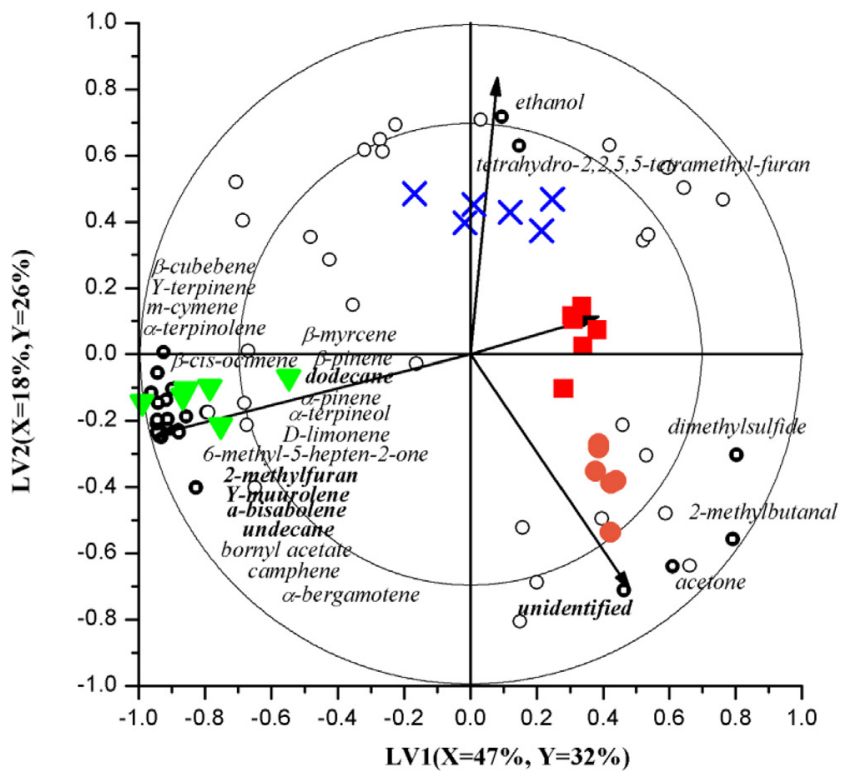

HPHT

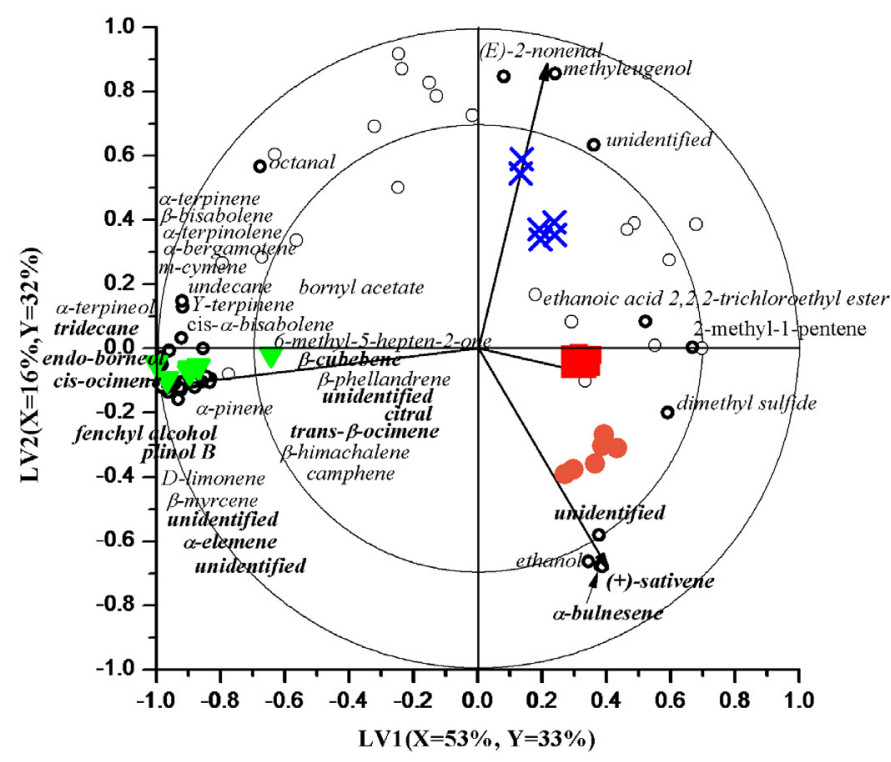

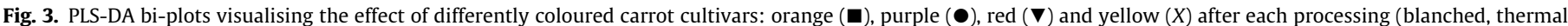

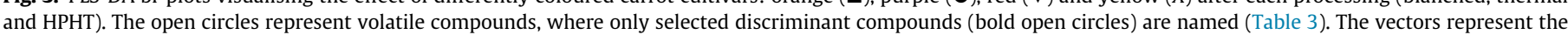

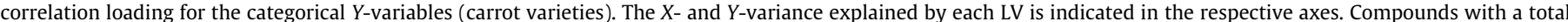

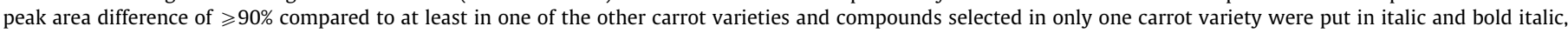
respectively. (For interpretation of the references to colour in this figure legend, the reader is referred to the web version of this article.) 
Table 3

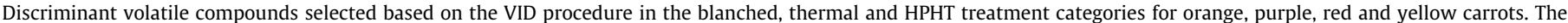

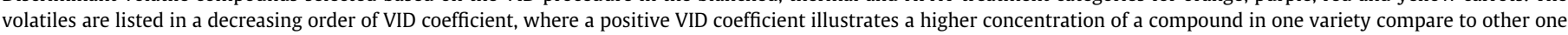

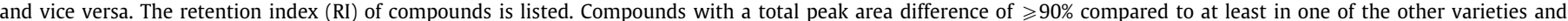
compounds selected in only one carrot varieties were put in italic and bold italic, respectively.

\begin{tabular}{|c|c|c|c|c|c|c|c|c|c|c|c|c|}
\hline & \multicolumn{3}{|c|}{ Orange carrot } & \multicolumn{3}{|c|}{ Purple carrot } & \multicolumn{3}{|c|}{ Red carrot } & \multicolumn{3}{|c|}{ Yellow carrot } \\
\hline & VID & Identity & RI & VID & Identity & RI & VID & Identity & RI & VID & Identity & RI \\
\hline \multirow[t]{25}{*}{ Blanched } & & & & $\begin{array}{l}-0.917 \\
-0.821\end{array}$ & $\begin{array}{l}\text { 3-Thujene } \\
\alpha \text {-Terpinene }\end{array}$ & $\begin{array}{l}926 \\
1017\end{array}$ & & & & & & \\
\hline & 0.839 & 2,4-Dimethyl-1-heptene & 846 & 0.896 & Myristicin & 1528 & 0.814 & Heptanal & 902 & 0.875 & Germacrene-D & 1503 \\
\hline & 0.863 & Toluene & 789 & & & & 0.874 & Hexanal & 812 & 0.913 & Ethanol & 699 \\
\hline & 0.887 & 2-Methyl-1-pentene & 715 & & & & 0.929 & $\alpha$-Terpinene & 1017 & & & \\
\hline & 0.921 & Acetone & 702 & & & & 0.936 & Terpinolene & 1090 & & & \\
\hline & & & & & & & 0.939 & $\alpha$-Pinene & 932 & & & \\
\hline & & & & & & & 0.947 & D-limonene & 1029 & & & \\
\hline & & & & & & & 0.952 & $\alpha$-Bergamotene & 1446 & & & \\
\hline & & & & & & & 0.964 & $\begin{array}{l}\text { 6-Methyl-5- } \\
\text { hepten-2-one }\end{array}$ & 987 & & & \\
\hline & & & & & & & 0.966 & $\alpha$-Phellandrene & 1004 & & & \\
\hline & & & & & & & 0.974 & Ocimene & 1052 & & & \\
\hline & & & & & & & 0.983 & m-Cymene & 1025 & & & \\
\hline & & & & & & & 0.986 & $\beta$-Himachalene & 1543 & & & \\
\hline & & & & & & & 0.988 & $\gamma$-Terpinene & 1060 & & & \\
\hline & & & & & & & 0.992 & Nonane & 899 & & & \\
\hline & & & & & & & 0.992 & Camphene & 947 & & & \\
\hline & & & & & & & 0.993 & Bornyl acetate & 1290 & & & \\
\hline & & & & & & & 0.993 & $\beta$-Gurjunene & 1383 & & & \\
\hline & & & & & & & 0.994 & B-Cubebene & 1490 & & & \\
\hline & & & & & & & 0.995 & cis- $\alpha$-bisabolene & 1546 & & & \\
\hline & & & & & & & 0.995 & Undecane & 1101 & & & \\
\hline & & & & & & & 0.996 & Tridecane & 1307 & & & \\
\hline & & & & & & & 0.997 & $\beta$-Myrcene & 991 & & & \\
\hline & & & & & & & 0.998 & cis-ocimene & 1041 & & & \\
\hline & & & & & & & 0.998 & 2- $\beta$-Pinene & 974 & & & \\
\hline \multirow[t]{19}{*}{ Thermal } & & & & 0.839 & Acetone & 702 & 0.838 & $\alpha$-Bergamotene & 1446 & 0.823 & Ethanol & 699 \\
\hline & & & & 0.851 & Dimethyl sulfide & 705 & 0.851 & Dodecane & 1200 & 0.852 & $\begin{array}{l}\text { Tetrahydro-2,2,5,5- } \\
\text { tetramethyl-furan }\end{array}$ & 776 \\
\hline & & & & 0.931 & Unidentified & 1658 & 0.877 & Bornyl acetate & 1290 & & & \\
\hline & & & & 0.961 & 2-Methylbutanal & 736 & 0.883 & Camphene & 947 & & & \\
\hline & & & & & & & 0.888 & m-Cymene & 1024 & & & \\
\hline & & & & & & & 0.894 & $\alpha$-Terpinolene & 1095 & & & \\
\hline & & & & & & & 0.910 & $\alpha$-Pinene & 932 & & & \\
\hline & & & & & & & 0.931 & $\beta$-Cubebene & 1490 & & & \\
\hline & & & & & & & 0.931 & $\beta$-Myrcene & 992 & & & \\
\hline & & & & & & & 0.933 & $\begin{array}{l}\text { 6-Methyl-5-hepten- } \\
\text { 2-one }\end{array}$ & 987 & & & \\
\hline & & & & & & & 0.934 & Undecane & 1101 & & & \\
\hline & & & & & & & 0.939 & $\alpha$-Bisabolene & 1573 & & & \\
\hline & & & & & & & 0.943 & $\gamma$-Muurolene & 1382 & & & \\
\hline & & & & & & & 0.943 & 2-Methylfuran & 718 & & & \\
\hline & & & & & & & 0.944 & $\gamma$-Terpinene & 1060 & & & \\
\hline & & & & & & & 0.944 & $\beta$-Pinene & 975 & & & \\
\hline & & & & & & & 0.946 & D-limonene & 1029 & & & \\
\hline & & & & & & & 0.947 & $\alpha$-Terpineol & 1192 & & & \\
\hline & & & & & & & 0.969 & $\beta$-cis-Ocimene & 1050 & & & \\
\hline \multirow[t]{17}{*}{ HPHT } & & & & -0.807 & Octanal & 1003 & & & & & & \\
\hline & 0.852 & $\begin{array}{l}\text { Ethanoic acid 2,2,2- } \\
\text { trichloroethyl ester }\end{array}$ & 717 & 0.804 & Unidentified & 1589 & 0.837 & Unidentified & 1524 & 0.826 & Unidentified & 1658 \\
\hline & 0.879 & 2-Methyl-1-pentene & 715 & 0.835 & Ethanol & 699 & 0.841 & Citral & 1279 & 0.872 & (E)-2-nonenal & 1161 \\
\hline & 0.916 & Dimethyl sulfide & 705 & 0.907 & $\alpha$-Bulnesene & 1416 & 0.852 & $\beta$-Phellandrene & 971 & 0.949 & Methyleugenol & 1407 \\
\hline & & & & 0.911 & (+)-Sativene & 1457 & 0.854 & $\alpha$-Bergamotene & 1446 & & & \\
\hline & & & & & & & 0.865 & $\beta$-Cubebene & 1490 & & & \\
\hline & & & & & & & 0.875 & Bornyl acetate & 1290 & & & \\
\hline & & & & & & & 0.882 & $\beta$-Himachalene & 1543 & & & \\
\hline & & & & & & & 0.888 & Camphene & 946 & & & \\
\hline & & & & & & & 0.890 & $\begin{array}{l}\text { 6-Methyl-5-hepten- } \\
\text { 2-one }\end{array}$ & 987 & & & \\
\hline & & & & & & & 0.908 & $\beta$-Bisabolene & 1534 & & & \\
\hline & & & & & & & 0.911 & $\alpha$-Terpinene & 1061 & & & \\
\hline & & & & & & & 0.920 & $\alpha$-Terpinolene & 1091 & & & \\
\hline & & & & & & & 0.929 & Unidentified & 1055 & & & \\
\hline & & & & & & & 0.930 & Unidentified & 1387 & & & \\
\hline & & & & & & & 0.934 & $\alpha$-Pinene & 932 & & & \\
\hline & & & & & & & 0.934 & Trans- $\beta$-ocimene & 1049 & & & \\
\hline
\end{tabular}


Table 3 (continued)

\begin{tabular}{|c|c|c|c|c|c|c|c|c|c|c|c|}
\hline \multicolumn{3}{|c|}{ Orange carrot } & \multicolumn{3}{|c|}{ Purple carrot } & \multicolumn{3}{|c|}{ Red carrot } & \multicolumn{3}{|c|}{ Yellow carrot } \\
\hline VID & Identity & RI & VID & Identity & RI & VID & Identity & RI & VID & Identity & RI \\
\hline & & & & & & 0.942 & $\beta$-myrcene & 991 & & & \\
\hline & & & & & & 0.948 & $\alpha$-Elemene & 1383 & & & \\
\hline & & & & & & 0.960 & m-Cymene & 1025 & & & \\
\hline & & & & & & 0.967 & $\alpha$-Terpineol & 1191 & & & \\
\hline & & & & & & 0.972 & D-limonene & 1029 & & & \\
\hline & & & & & & 0.976 & Tridecane & 1307 & & & \\
\hline & & & & & & 0.976 & Endo-borneol & 1167 & & & \\
\hline & & & & & & 0.979 & Plinol B & 1149 & & & \\
\hline & & & & & & 0.984 & Undecane & 1101 & & & \\
\hline & & & & & & 0.986 & cis- $\alpha$-bisabolene & 1573 & & & \\
\hline & & & & & & 0.991 & Fenchyl alcohol & 1115 & & & \\
\hline & & & & & & 0.991 & cis-ocimene & 1041 & & & \\
\hline & & & & & & 0.994 & $\gamma$-Terpinene & 1060 & & & \\
\hline
\end{tabular}

these volatiles were detected at higher levels in the conventional thermal processed samples. Since such low-odour threshold volatile compounds are associated with undesirable off-flavour of processed plant foods (Cremer et al., 2000a), their reduced formation under HPHT treatment could be an interesting aspect and should be further investigated from a sensorial point of view.

The trend with respect to both reaction pathways (i.e. fatty acid and Strecker degradation, respectively) was consistently observed when process impact was compared per carrot cultivar. In our previous study (Kebede et al. (2013)), a similar result was observed despite the fact that the study was conducted on different types of vegetables - broccoli, green pepper and spinach. Based on the results of the present work, two general conclusions can be drawn: firstly, HPHT processing in comparison to equivalent conventional thermal processing enhances the formation of oxidative reaction products. In that context, the effect of high pressure on the solubility of oxygen may play an important role and this requires further investigation (Ramirez et al., 2009). Secondly, HPHT processing, in comparison to its conventional counterpart, seems to reduce the formation of Maillard reaction and Strecker degradation products. In that context, the following hypotheses have been reported: (i) reduced thermal load to which the product is exposed during HPHT processing, mainly due to the fast compression heating and decompression cooling (Jaeger et al., 2010); (ii) pressure may enhance pathways that produce fewer intermediate volatile compounds (Hill et al., 1999). In addition, Jaeger et al. (2010) indicated the need to investigate whether the different effect of pressure on proteins may influence the effect of high pressure processing on Maillard reaction. A combination of all of these possibilities may also be involved.

\subsection{Effect of differently coloured carrot cultivars after processing}

When the process-impact was compared per carrot cultivar, in addition to the general trends on process-induced chemical reactions, some exceptions could also be found. These exceptions can be related to differences in the natural chemical composition (e.g., carotenoids, free sugar and phenolic compounds) between the differently coloured carrots. Therefore, in this last step of the comparative analysis, the effect of carrot cultivars (orange, purple, red and yellow) was investigated after processing (i.e. blanched, thermal and HPHT). In each case, a PLS-DA model was constructed using $3 \mathrm{LVs}$, in which the respective bi-plots are shown in Fig. 3. Independently from the processing condition, red carrot is clearly separated from the other cultivars, indicating that its volatile fraction is distinct. This is in agreement with the discussion in Fig. 1. As previously mentioned, blanched yellow and orange carrots showed comparable chromatograms, whereas purple carrots were characterised by fewer volatile compounds detected. This observation is confirmed by Fig. 3 as there is grouping between blanched orange and yellow carrots (before sterilisation). The similarity of their volatile fractions can also be deduced from the overlapping vectors (correlation loading for the respective classes). The class of blanched purple carrots, in another case, is projected away from the blanched orange and yellow cultivars. However, after both thermal and HPHT sterilisation, the orange and yellow carrots were also separated from each other. The variance among carrot varieties ( $Y$-variance) that is explained with the first two LVs is $65 \%$, $58 \%$ and $65 \%$ after blanching and thermal and HPHT sterilisation, respectively.

In order to rank volatiles based on their concentration in one carrot cultivar compared to the other, VID coefficients were calculated. In blanched carrots, the selected volatiles can be categorised under the chemical classes of terpenes, hydrocarbons, aliphatic aldehydes and ketones. In thermally sterilised carrots, terpenes, furanic compounds, sulfur-containing compounds, Strecker aldehydes and ketones were selected. Terpenes and terpene alcohols, sulfur-containing compounds, hydrocarbons, aliphatic aldehydes and ketones were chosen in HPHT sterilised carrots. Nevertheless, as can be seen from Table 3, in both blanched and sterilised samples, higher numbers of terpenes were selected with a positive VID in red carrot compared to the other cultivars, indicating their presence at high concentrations. As previously discussed, Kreutzmann et al. (2008) observed that red carrot was characterised by higher intensities in green aroma, bitterness and burning aftertaste, which are terpene-related flavour attributes. The authors underlined the importance of colour genotype on chemical composition and sensory quality of carrots. Similarly, the present work demonstrated that the variation as a result of the difference in the natural chemical composition, mainly between red carrot and the other cultivars, was greater than the variance due to the applied processing techniques. In other words, due to the high amount of terpenes in red carrot, other process-induced chemical reaction products seem to be completely overshadowed when selecting discriminative volatile compounds.

\section{Conclusions}

This comparative study enabled the determination of two important quality-related chemical reactions which were differently affected by HPHT sterilisation and an equivalent conventional thermal sterilisation, namely oxidative degradation and the Maillard reaction. In the case of the first reaction, HPHT sterilisation enhanced oxidative degradation of terpenes, free fatty acids, phenylpropanoids and carotenoids, leading to an increased formation of the respective reaction products. In the second case, HPHT sterilisation seems to reduce formation of Maillard reaction and Strecker degradation products, since lower amounts of furanic 
compounds and Strecker aldehydes were detected in HPHT sterilised carrots than in conventionally sterilized carrots.

Based on the present experimental set-up, it is difficult to evaluate to what extent changes induced by high pressure affect overall carrot flavour. As shown, a complex mixture of terpenes, aldehydes, alcohols and sulfur and furanic compounds are considered responsible for flavour of processed carrot. Due to interactions between individual flavour compounds, even minor changes in the concentration of one compound may have a major impact on the overall flavour. Therefore, it is obvious that sensory analysis is needed for a better understanding of the HPHT effects on the overall sensory properties of carrots.

This study clearly showed the power of the followed untargeted multivariate approach as a fast screening tool to zoom into relevant reaction pathways within a complex of chemical changes occurring during food processing. As a next step, kinetic studies should be performed to increase insight into the way HPHT processing affects oxidative degradation and Maillard reactions. Each reaction should be separately studied to (i) confirm the observed different effects of HPHT processing and (ii) to add depth to the effect of HPHT processing variable on the different stages of these reactions (e.g., using a targeted multi-response approach). Furthermore, the identity of proposed potential markers (e.g. 1-octen-3ol) should be confirmed using pure standard samples. Subsequently, a single-response kinetic study should be performed to increase insight into the impact of each of the HPHT processing variables, aiming at process design and optimisation.

\section{Acknowledgements}

This work was financially supported by KU Leuven Research Fund. One of the authors (T.G.) is a postdoctoral researcher funded by the Research Foundation Flanders (FWO) while S.P. was funded by the Agency for Innovation by Science and Technology in Flanders (IWT-Vlaanderen).

The authors thank Heidi Roba and Margot De Haes for their laboratory assistance and acknowledge Agilent technologies, Diegem, Belgium for providing the Mass Profiler professional (MPP) software.

\section{References}

Adebooye, O. C., Vijayalakshmi, R., \& Singh, V. (2008). Peroxidase activity, chlorophylls and antioxidant profile of two leaf vegetables (Solanum nigrum L. and Amaranthus cruentus L.) under six pretreatment methods before cooking. International Journal of Food Science and Technology, 43(1), 173-178.

Alasalvar, C., Grigor, J. M., Zhang, D. L., Quantick, P. C., \& Shahidi, F. (2001) Comparison of volatiles, phenolics, sugars, antioxidant vitamins, and sensory quality of different colored carrot varieties. Journal of Agricultural and Food Chemistry, 49(3), 1410-1416.

Araya, X. I. T., Smale, N., Zabaras, D., Winley, E., Forde, C., Stewart, C. M., et al. (2009). Sensory perception and quality attributes of high pressure processed carrots in comparision to raw, sous-vide and cooked carrots. Innovative Food Science \& Emerging Technologies, 10(1), 420-433.

Brown, G. (2004). Modelling and optimising retort temperature control. In P. Richardson (Ed.), Improving the Thermal Processing of Foods (pp. 105-124). Cambridge: Woodhead Publishing Limited and CRC Press LLC.

Can Baser, K. H., \& Demirci, F. (2007). Chemistry of essential oils. In R. G. Berger (Ed.), Flavours and Fragrances (pp. 43-86). Hannover: Springer.

Christensen, L. P., Edelenbos, M., \& Kreutzmann, S. (2007). Fruits and vegetables of moderate climate. In R. G. Berger (Ed.), Flavours and Fragrances Chemistry, Bioprocessing and Sustainability (pp. 135-181). Berlin: Springer.

Cremer, D. R. \& Eichner, K. (2000a). Formation of volatile compounds during heating of spice paprika (Capsicum annuum) powder. Journal of Agricultural and Food Chemistry, 48(6), 2454-2460.

Cremer, D. R. \& Eichner, K. (2000b). The reaction kinetics for the formation of Strecker aldehydes in low moisture model systems and in plant powders. Food Chemistry, 71(1), 37-43.

Crouzet, J. (2000). Thermal generation of carotenoid-derived aroma compounds Abstracts of Papers American Chemical Society, 219(1-2), 5.
De Heij, W., Van Schepdael, L., Moezelaar, R., Hoogland, H., Matser, A., \& Van den Berg, R. (2003). High pressure sterilization: Maximizing the benefits of adiabatic heating. Food Technology, 57(3), 37-41.

De Vleeschouwer, K., Van der Plancken, I., Van Loey, A., \& Hendrickx, M. E. (2010). The effect of high pressure-high temperature processing conditions on acrylamide formation and other maillard reaction compounds. Journal of Agricultural and Food Chemistry, 58(22), 11740-11748.

Duan, H. Y., \& Barringer, S. A. (2012). Changes in furan and other volatile compounds in sliced carrot during air-drying. Journal of Food Processing and Preservation, 36(1), 46-54.

Grauwet, T., Rauh, C., Van der Plancken, I., Vervoort, L., Hendrickx, M., Delgado, A., et al. (2012). Potential and limitations of methods for temperature uniformity mapping in high pressure thermal processing. Trends in Food Science E Technology, 23(2), 97-110.

Grauwet, T., Van der Plancken, I., Vervoort, L., Hendrickx, M., \& Van Loey, A. (2010). Protein-based indicator system for detection of temperature differences in high pressure high temperature processing. Food Research International, 43(1), 862-871.

Hampel, D., Mosandl, A., \& Wust, M. (2005). Biosynthesis of mono- and sesquiterpenes in carrot roots and leaves (Daucus carota L.): Metabolic cross talk of cytosolic mevalonate and plastidial methylerythritol phosphate pathways. Phytochemistry, 66(3), 305-311.

Heatherb, D. A., Wrolstad, R. E., \& Libbey, L. M. (1971). Carrot volatiles. 1. Characterization and effects of canning and freeze drying. Journal of Food Science, 36(2), 219.

Hill, V. M., Isaacs, N. S., Ledward, D. A., \& Ames, J. M. (1999). Effect of high hydrostatic pressure on the volatile components of a glucose-lysine model system. Journal of Agricultural and Food Chemistry, 47(9), 3675-3681.

Howard, L. R., Braswell, D., Heymann, H., Lee, Y., Pike, L. M., \& Aselage, J. (1995). Sensory attributes and instrumental analysis relationships for strained processed carrot flavor. Journal of Food Science, 60(1), 145-148.

Jaeger, H., Janositz, A., \& Knorr, D. (2010). The Maillard reaction and its control during food processing. The potential of emerging technologies. Pathologie Biologie, 58(3), 207-213.

Jones, M. J. (2008). Formation of vegetable flavour. In B. Brückner \& S. Grant Wyllie (Eds.), Fruit and Vegetable Flavour Recent Advances and Future Prospects (pp. 71-96). Cambridge: Woodhead Publishing Limited.

Kanasawud, P., \& Crouzet, J. C. (1990). Mechanism of formation of volatile compounds by thermal-degradation of carotenoids in aqueous-medium. 2. Lycopene degradation. Journal of Agricultural and Food Chemistry, 38(5), $1238-1242$.

Kebede, B. T., Grauwet, T., Tabilo-Munizaga, G., Palmers, S., Vervoort, L., Hendrickx, M., et al. (2013). Headspace components that discriminate between thermal and high pressure high temperature treated green vegetables: Identification and linkage to possible process induced chemical changes. Food Chemistry, 141, 1603-1613.

Kerler, J., Winkel, C., Davidek, T., \& Blank, I. (2010). Basic chemistry and process conditions for reaction flavours with particular focus on Maillard-type reactions. In A. J. Taylor \& R. S. T. Linforth (Eds.), Food Flavour Technology (pp. 51-81). Blackwell Publishing Ltd.

Kjeldsen, F., Christensen, L. P., \& Edelenbos, M. (2003). Changes in volatile compounds of carrots (Daucus carota L.) during refrigerated and frozen storage. Journal of Agricultural and Food Chemistry, 51(18), 5400-5407.

Kramer, M., Bufler, G., Nothnagel, T., Carle, R., \& Kammerer, D. R. (2012a). Effects of cultivation conditions and cold storage on the polyacetylene contents of carrot (Daucus carota L.) and parsnip (Pastinaca sativa L.). Journal of Horticultural Science E Biotechnology, 87(2), 101-106.

Kramer, M., Bufler, G., Ulrich, D., Leitenberger, M., Conrad, J., Carle, R., et al. (2012b) Effect of ethylene and 1-methylcyclopropene on bitter compounds in carrots (Daucus carota L.). Postharvest Biology and Technology, 73, 28-36.

Kreutzmann, S., Thybo, A. K., Edelenbos, M., \& Christensen, L. P. (2008). The role of volatile compounds on aroma and flavour perception in coloured raw carrot genotypes. International Journal of Food Science and Technology, 43(9), 1619-1627.

Leja, M., Kaminska, I., Kramer, M., Maksylewicz-Kaul, A., Kammerer, D., Carle, R. et al. (2013). The content of phenolic compounds and radical scavenging activity varies with carrot origin and root color. Plant Foods for Human Nutrition, 68(2), 163-170.

Limacher, A., Kerler, J., Conde-Petit, B., \& Blank, I. (2007). Formation of furan and methylfuran from ascorbic acid in model systems and food. Food Additives and Contaminants, 24, 122-135.

Mark, J., Pollien, P., Lindinger, C., Blank, I., \& Mark, T. (2006). Quantitation of furan and methylfuran formed in different precursor systems by proton transfer reaction mass spectrometry. Journal of Agricultural and Food Chemistry, 54(7), 2786-2793.

Matser, A. M., Krebbers, B., Van den Berg, R. W., \& Bartels, P. V. (2004). Advantages of high pressure sterilisation on quality of food products. Trends in Food Science $\mathcal{E}$ Technology, 15(2), 79-85.

Mottram, D. S. (2007). The Maillard reaction: Source of flavour in thermally processed foods. In R. G. Berger (Ed.), Flavours and Fragrances Chemistry, Bioprocessing and Sustainability (pp. 269-282). Berlin: Springer.

Nicolle, C., Simon, G., Rock, E., Amouroux, P., \& Remesy, C. (2004). Genetic variability influences carotenoid, vitamin, phenolic, and mineral content in white, yellow, purple, orange, and dark-orange carrot cultivars. Journal of the American Society for Horticultural Science, 129(4), 523-529. 
Oey, I., Van der Plancken, I., Van Loey, A., \& Hendrickx, M. (2008). Does high pressure processing influence nutritional aspects of plant based food systems? Trends in Food Science E Technology, 19(6), 300-308.

Owczarek-Fendor, A., De Meulenaer, B., Scholl, G., Adams, A., Van Lancker, F., Eppe, G., et al. (2011). Furan formation from lipids in starch-based model systems, as influenced by interactions with antioxidants and proteins. Journal of Agricultural and Food Chemistry, 59(6), 2368-2376.

Ramirez, R., Saraiva, J., Lamela, C. P., \& Torres, J. A. (2009). Reaction kinetics analysis of chemical changes in pressure-assisted thermal processing. Food Engineering Reviews, 1(1), 16-30.

Reineccius, A. (2006). Flavor Chemisrty and Technology. Taylor \& Francis Group.

Simon, P. W. (1982). Effect of genotype, growing conditions, storage and processing on carrot (Daucus Carota L.) flavor. Abstracts of Papers of the American Chemical Society, 184 (SEP), 28-AGFD.

Valdez-Fragoso, A., Mujica-Paz, H., Welti-Chanes, J., \& Torres, J. A. (2011). Reaction kinetics at high pressure and temperature: Effects on milk flavor volatiles and on chemical compounds with nutritional and safety importance in several foods. Food and Bioprocess Technology, 4(6), 986-995.

Van der Plancken, I., Verbeyst, L., De Vleeschouwer, K., Grauwet, T., Heinio, R. L. Husband, F. A., et al. (2012). (Bio)chemical reactions during high pressure/high temperature processing affect safety and quality of plant-based foods. Trends in Food Science \& Technology, 23(1), 28-38.

Verbeyst, L., Bogaerts, R., Van der Plancken, I., Hendrickx, M., \& Van Loey, A. (2012). Modelling of vitamin C degradation during thermal and high-pressure treatments of red fruit. Food Bioprocess Technology, 6, 1015-1023.

Vervoort, L., Grauwet, T., Kebede, B. T., Van der Plancken, L., Timmermans, R. Hendrickx, M., et al. (2012a). Headspace fingerprinting as an untargeted approach to compare novel and traditional processing technologies: A casestudy on orange juice pasteurisation. Food Chemistry, 134(4), 2303-2312.

Vervoort, L., Grauwet, T., Njoroge, D. M., Van der Plancken, I., Matser, A., Hendrickx M., et al. (2013). Comparing thermal and high pressure processing of carrots at different processing intensities by headspace fingerprinting. Innovative Food Science E' Emerging Technologies, 18, 31-42.

Vervoort, L., Van der Plancken, L., Grauwet, T., Verlinde, P., Matser, A., Hendrickx, M., et al. (2012b). Thermal versus high pressure processing of carrots: comparative pilot-scale study on equivalent basis. Innovative Food Science $\mathcal{E}$ Emerging Technologies, 15, 1-13.

Wilson, D. R., Dabrowski, L., Stringer, S., Moezelaar, R., \& Brocklehurst, T. F. (2008). High pressure in combination with elevated temperature as a method for the sterilisation of food. Trends in Food Science E Technology, 19(6), 289-299. 